\title{
Humoral immune response to selective mycobacterial antigens and serodiagnosis of active tuberculosis in Bangladeshi patients
}

\author{
Md. Mohiuddin and J. Ashraful Haq \\ Department of Microbiology, Ibrahim Medical College, 122 Kazi Nazrul Islam Avenue, Dhaka, Bangladesh
}

\begin{abstract}
Background and objective: Serological test has become an important tool in the diagnosis of TB cases. This study focused on the analysis and comparison of antibody response to two Mycobacterium tuberculosis (MTB) antigens namely Ag85 complex and culture filtrate protein (CFP) in patients with tuberculosis. Antibody response to specific antigen was utilized as a diagnostic tool to detect active tuberculosis (TB) cases.

Methods: Sera from 30 patients with active tuberculosis and 30 healthy individuals were tested by enzyme linked immunosorbent assay (ELISA) for the presence of immunoglobulin (Ig) $\mathrm{G}$ and IgM antibodies against Ag85 complex and culture filtrate protein (CFP) antigens of MTB.

Results: The mean OD values of serum IgM and IgG antibodies against Ag85 and CFP were significantly $(\mathrm{p}<0.0001)$ higher in patients than that of healthy control individuals. Among the 30 tuberculosis patients, anti-Ag85 complex IgM and IgG was positive in $66.7 \%$ and $70.0 \%$ patients respectively. The seropositive rate of anti-CFP IgM and IgG was $33.3 \%$ and $56.7 \%$ respectively. The sensitivity and specificity of anti Ag85 and anti-CFP IgM and IgG ranged from $60.0 \%$ to $96.7 \%$.

Conclusion: The study demonstrated that determination of IgM and IgG antibodies against Ag85 complex and CFP could be used as a serological marker for diagnosis of active tuberculosis.
\end{abstract}

IMC J Med Sci 2016; 10(2): 53-57

\section{Introduction}

Tuberculosis (TB) caused by Mycobacterium tuberculosis (MTB) is one of the leading cause of morbidity and death in the world. In 2015, there were about 10.4 million new TB cases worldwide and 1.4 million deaths from TB [1]. The estimated annual incidence of TB in Bangladesh is 0.362 million cases [1]. Early diagnosis and treatment of TB patients is crucial for the control of TB [2]. In developing countries, current diagnosis of TB largely relies on clinical symptoms, radiographic evidence supported by presence of acid fast bacilli in smear and isolation of MTB by culture from the clinical specimen. Direct smear is fast and cheap method but it lacks sensitivity. Culture method is more sensitive but it is cumbersome and requires longer incubation period. In the recent years, the detection of MTB-specific antibodies has become important diagnostic aid in the diagnosis of $\mathrm{TB}$ especially in smear-negative sputum cases [3]. It is particularly important for pediatric and extra pulmonary tuberculosis and in those unable to produce sputum. Thus the antibody assay might be of great benefit for early diagnosis and control of TB.

MTB infection can be categorized into three main stages: latent, reactivating, and active TB. Each stage represents differences in MTB gene

Address for Correspondence:

Prof. J. Ashraful Haq, Department of Microbiology, Ibrahim Medical College, 122 Kazi Nazrul Islam Avenue, Dhaka, Bangladesh.Email: jahaq54@yahoo.com 
expression and hence antibody response to MTB infection varies in different stages of tubercular infection due to presence of stage specific antigens [4]. Hsp16.3 is secreted during the latent phase of mycobacterial growth and is an important component that facilitates the survival of MTB during latent human infection [5]. Immune responses to MTB antigens ESAT6, CFP10 and Ag85B have been shown to be significantly higher in active TB than in latent TB [6]. Thus, it is rational to evaluate the antibodies to MTB antigens in serodiagnosis of active or latent $\mathrm{TB}$ infection. However, the proteins of MTB induce a variable degree of humoral immune responses in infected people.

Serological methods have been regarded as attractive tools for rapid diagnosis of tuberculosis due to their simplicity, rapidity and low cost. Serodiagnosis also does not require safety measures associated with handling of live bacilli as in culture and offer the possibility of detecting cases often missed by routine sputum smear microscopy. It is estimated that a rapid and widely available diagnostic assay with $85 \%$ sensitivity and $95 \%$ specificity would result in 400,000 fewer deaths each year and would greatly reduce the global health cost of TB [7].

Antigen85 complex and CFP M. tuberculosis elicits detectable IgG response in tuberculosis patients. Sensitivity and specificity of assays utilizing Ag85 complex have been reported to range from $82-84.1 \%$ and $85.2-86 \%$ respectively [8]. Serological tests detecting IgG antibody against CFP showed sensitivity and specificity of 60.4 to $66 \%$ and 73.8 to $85.2 \%$ respectively [9-11].

Many studies have been conducted to evaluate the humoral immune response to different tubercular antigens and to find out the ideal candidate antigens for serological test to detect active tubercular infection. The success is so far variable as antibody response to TB infection may vary due to stage of infection and the heterogeneity of the geographical background of the population [12]. Until today, there is no reported study on humoral immune response to specific MTB antigens in Bangladeshi population either in active tuberculosis patients or in healthy people.
Therefore, the present study was undertaken to determine the antibody response to two different MTB antigens namely Ag85 complex and CFP in cases with active TB infection.

\section{Materials and methods}

The study was conducted in the Department of Microbiology, Bangladesh Institute of Research and Rehabilitation in Diabetes, Endocrine and Metabolic Disorders (BIRDEM), Dhaka. Informed consent was obtained from each of the participant.

Study population: Study included thirty adult confirmed active pulmonary tuberculosis cases. Active TB cases were confirmed by clinical features, positive AFB sputum and culture. Age and sex matched thirty healthy individuals were enrolled in the study as healthy control. All the healthy individuals were BCG vaccinated and neither they nor any of their family members had history or any sign symptoms of tuberculosis. About $5 \mathrm{ml}$ of blood was collected from each participant with aseptic precautions by venipuncture. The serum was immediately separated and stored at $-20^{\circ} \mathrm{C}$ until used.

Antigens: Two MTB antigens were used namely Ag85 complex and culture filtrate protein (CFP). The antigens were obtained from the Department of Microbiology, Immunology and Pathology, Colorado State University, 1682 Campus Delivery, Fort Collins, CO 80523, USA.

Detection of antibody by ELISA: Antibody to specific MTB antigens was determined by enzyme linked immunosorbent assay (ELISA). IgM and IgG antibodies against Ag85 complex and CFP were determined. ELISA was performed as described by Voller et al [13]. Each of the antigens was diluted in carbonate/bicarbonate buffer $(\mathrm{pH}$ 9.6) at a concentration of $5 \mu \mathrm{g} / \mathrm{ml}$. The optimum working concentration of each antigen was predetermined by checkerboard method using antigen concentration of $2.5 \mu \mathrm{g} / \mathrm{ml}, 5 \mu \mathrm{g} / \mathrm{ml}$ and 10 $\mu \mathrm{g} / \mathrm{ml}$. To coat the wells of 96 well EIA microtitre plate, $100 \mu \mathrm{l}$ of diluted antigens $(5 \mu \mathrm{g} / \mathrm{ml})$ was added to each well. Plate was covered with plastic cover and was incubated at $37^{\circ} \mathrm{C}$ for 2 hours. Then antigen coating solution was removed and the plate was washed 3 times by filling the wells with $250 \mu$ l 
of PBS-0.05\% Tween 20 (PBS-T, pH 7.2). The wells were blocked by adding $200 \mu \mathrm{l}$ of blocking buffer (2\% BSA in PBS-T) by incubating at $4{ }^{\circ} \mathrm{C}$ for overnight. Then the plate was washed 3 times with PBS-T and $100 \mu \mathrm{l}$ of sera diluted in PBS-T with $0.1 \%$ BSA buffer (1:400 for IgM and 1:1600 for $\mathrm{IgG}$ ) were added to each well and incubated at $37^{\circ} \mathrm{C}$ for $2 \mathrm{hrs}$. After incubation, the plate was washed 3 times with PBS-T. Then $100 \mu \mathrm{l}$ of $\operatorname{IgM}$ or IgG anti-human-HRP conjugate was added in each well at a dilution of 1:5000 (MP Biomedicals, USA) and kept at $37^{\circ} \mathrm{C}$ for 2 hours. The plate was washed 3 times with PBS-T and then $50 \mu$ l of TMB substrate was added in each well and kept for 30 minutes at dark at room temperature. Then $50 \mu \mathrm{l}$ of $1 \mathrm{M}$ sulfuric acid was added as stop solution in each well and absorbance was read at 450nm in Human ELISA reader. Initially, checkerboard method was used to optimize the working serum dilution.

Interpretation of the result: The concentration of antibody was expressed in OD at a particular dilution of both patient and healthy control samples. In order to diagnose active tuberculosis cases by detecting IgM and $\mathrm{IgG}$ antibody response against specific antigens, a cut off $O D$ value was determined by the following formula:

Cut off OD value $=$ Mean antibody $(\operatorname{IgM} / \operatorname{IgG})$ titer of healthy participants against specific antigen $+2 \mathrm{xSD}$.

Any OD value above the cut off was considered as positive for respective antibodies. Significance of difference of mean OD value of $\operatorname{IgM}$ and $\operatorname{IgG}$ antibodies against respective antigens was calculated by independent student's $\mathrm{t}$ test.

\section{Results}

Antibody response to Ag85 complex and CFP was determined in sera of 30 confirmed cases of tuberculosis and 30 healthy individuals. IgM and IgG response against specific antigens were determined by ELISA method and concentration of antibodies was expressed in terms of OD value. Table-1 shows the antibody response to two mycobacterial antigens. It was observed that mean OD values of serum $\operatorname{IgM}$ and $\operatorname{IgG}$ antibodies against Ag85 complex and CFP were significantly higher in patients $(\mathrm{p}<0.0001)$ than that of healthy control subjects.

Table-1: Antibody response to different MTB antigens in tuberculosis and healthy participants

\begin{tabular}{lcccc}
\hline \multirow{2}{*}{$\begin{array}{l}\text { Study } \\
\text { population }\end{array}$} & \multicolumn{4}{c}{ Antibody to (Mean OD \pm SE) } \\
\cline { 2 - 5 } & Ag85 Complex & \multicolumn{2}{c}{ CFP } \\
\cline { 2 - 5 } & IgM & IgG & IgM & IgG \\
\hline $\begin{array}{l}\text { TB patients } \\
n=30\end{array}$ & $1.18 \pm 0.10$ & $1.51 \pm 0.13$ & $0.78 \pm 0.10$ & $1.32 \pm 0.11$ \\
$\begin{array}{l}\text { Healthy } \\
n=30\end{array}$ & $0.56 \pm 0.03$ & $0.87 \pm 0.07$ & $0.39 \pm 0.03$ & $0.57 \pm 0.07$ \\
p value & 0.0001 & 0.0001 & 0.0004 & 0.0001 \\
\hline
\end{tabular}

The diagnostic cut off OD values of anti-Ag85 complex $\operatorname{IgM}$ was 0.88 and $\mathrm{IgG}$ was 1.66 respectively. The cut off OD value of anti-CFP IgM was 0.77 and anti-CFP IgG was 1.36 (Table 2 ). These cut off OD values were used to determine the seropositive cases among the confirmed tuberculosis cases.

Table-2: Diagnostic cut off OD values for IgM and IgG antibodies to Ag85 complex and CFP antigens

\begin{tabular}{lcccc}
\hline \multirow{2}{*}{ Antigen } & \multicolumn{2}{c}{$\begin{array}{l}\text { Mean serum OD } \pm \text { SD of } \\
\text { healthy individuals for }\end{array}$} & \multicolumn{2}{l}{$\begin{array}{l}\text { Cut off OD } \\
\text { value (Mean } \\
\text { OD +2xSD) }\end{array}$} \\
\cline { 2 - 5 } & \multicolumn{2}{l|}{ IgM } & IgG & \multicolumn{2}{l|}{ IgM } & IgG \\
\hline $\begin{array}{l}\text { Ag85 } \\
\text { complex }\end{array}$ & $0.56 \pm 0.16$ & $0.87 \pm 0.39$ & 0.88 & 1.66 \\
CFP & $0.39 \pm 0.18$ & $0.57 \pm 0.39$ & 0.75 & 1.36
\end{tabular}

Note: Cut off $O D$ values were calculated from antibody response in healthy individuals.

Table-3 shows the seropositive cases of tuberculosis patients by detecting $\operatorname{IgM}$ and $\operatorname{IgG}$ antibodies against Ag85 complex and CFP antigens. It was observed that among the total number of 30 tuberculosis patients, anti-Ag85 complex IgM was positive in $66.7 \%$ patients and its sensitivity and specificity was $75.0 \%$ and 96.7\% respectively. The anti-Ag85 complex IgG was positive in $70.0 \%$ of patients and its sensitivity and specificity was $76.9 \%$ and $93.75 \%$ respectively. The seropositive rate of anti-CFP IgM and $\operatorname{IgG}$ was $33.3 \%$ and $56.7 \%$ while the sensitivity and specificity was $60.0 \%$ and $96.7 \%$ respectively. 
Table-3: Serodiagnosis of tuberculosis patients by detecting IgM and IgG antibodies against $\mathrm{Ag} 85$ complex and CFP antigens

\begin{tabular}{lcccc}
\hline Antigen & $\begin{array}{c}\text { Antibody } \\
\text { isotype }\end{array}$ & $\begin{array}{c}\text { Positive } \\
\text { TB case } \\
\mathbf{n}(\%)\end{array}$ & $\begin{array}{c}\text { Sensitivity } \\
\text { (\%) }\end{array}$ & $\begin{array}{c}\text { Specificity } \\
\text { (\%) }\end{array}$ \\
\hline Ag85 & $\operatorname{lgM}$ & $20(66.7)$ & 75.0 & 96.7 \\
complex & IgG & $21(70.0)$ & 76.9 & 93.6 \\
CFP & IgM & $10(33.3)$ & 60.0 & 96.7 \\
& IgG & $17(56.7)$ & 69.8 & 93.6 \\
\hline
\end{tabular}

Note: True positive indicates- culture positive tuberculosis case True negative = healthy individuals with no history and clinical feature of $T B$.

\section{Discussion}

Although culture is regarded as the gold standard method for diagnosing active $\mathrm{TB}$, it is time consuming and requires 6-8 weeks for isolation of MTB from clinical specimen. The serological method may be an alternative tool to detect TB cases in resource limited settings because it is simple, rapid and inexpensive. It also offers the possibility of detecting cases often missed by standard sputum smear microscopy [7]. Humoral immune response to specific antigens may be used as a sero-marker to diagnose active TB cases as well as to understand their role in immunity or susceptibility to infection. In view of this, attempt has been made in this study to determine the humoral immune response to defined mycobacterial antigens. In the present study, 30 confirmed cases of tuberculosis and 30 healthy individuals were randomly selected to detect the $\operatorname{IgM}$ and IgG antibody against two mycobacterial antigens namely, Ag85 complex and culture filtrate protein.

Anti-Ag85 IgM and IgG response was found significantly higher $(\mathrm{p}<0.0001)$ among patients with active tuberculosis compared to that of healthy control individuals indicating that host induced antibody response to Ag85 (Table-1). Similar significantly higher IgM and IgG response was observed for CFP in active tuberculosis cases. The presence of low level of IgM and IgG antibodies against CFP in the sera of healthy subjects could be due to exposure to mycobacteria early in the life. The wide spread exposure to $M$. tuberculosis is indicated by high percentage of tuberculin positivity rate in our population.
Attempt was made to utilize antibody responses to these antigens as serological markers for diagnosis of active TB infection. For serodiagnosis, diagnostic OD cut off value was determined by adding 2xSD to the mean OD of antibody response to respective antigens of healthy people. It was observed that among the total number of 30 patients, anti-Ag85 complexes IgM was positive in $66.67 \%$ of patients and its sensitivity and specificity was $75.0 \%$ and $96.7 \%$ respectively (Table 3). The anti-Ag85 complex IgG was positive in $70.0 \%$ of patients and sensitivity and specificity was $76.9 \%$ and $93.75 \%$ respectively. However, poor sensitivity to Ag85 complex has also been reported in Malaysia population [14]. This might be due to difference in stages of infection and heterogeneity of the population in geographical background [12]. Anti-CFP IgM antibody was positive in $33.3 \%$ patients and sensitivity and specificity was $60.0 \%$ and $96.7 \%$ respectively. Anti-CFP IgG was positive in $56.7 \%$ of patients and sensitivity and specificity was $69.8 \%$ and $93.75 \%$ respectively. It appeared that IgM and IgG antibody response to Ag85 complex was better compared to that of CFP. Therefore, determination of $\operatorname{IgM}$ and $\operatorname{IgG}$ antibodies against Ag85 complex could be used as a serological marker for diagnosis of active tuberculosis in cases where other tests do not give conclusive information. It is particularly applicable in children where they are unable to provide sputum samples for either staining or culture. Further studies, are therefore, required to refine the serological tests for accurate diagnosis of active tuberculosis.

The present study has demonstrated that serological tests with specific MTB antigen may be used as an adjunct test for diagnosis of tuberculosis where other diagnostic tools are lacking or ineffective.

\section{References}

1. World Health Organization. Global tuberculosis report 2016. Geneva: World health organization; 2016. 214 p.

2. Steingart KR, Flores LL, Dendukuri N, Schiller I, Laal S, Ramsay A, et al. Commercial serological tests for the diagnosis of active pulmonary and extrapulmonary tuberculosis: an updated systematic review and 
meta-analysis. PLoS Med 2011; 8(8): e1001062. doi: 10.1371/journal.pmed.1001062.

3. Wu X, Yang Y, Zhang J, Li B, Lian Y, Zhang $\mathrm{C}$, Dong $\mathrm{M}$. Comparison of antibody responses to seventeen antigens from Mycobacterium tuberculosis. Clin Chim Acta 2010; 411(19-20): 1520-1528. doi: 10.1016/j.cca.2010.06.014

4. Sutherland JS, Lalor MK, Black GF, Ambrose LR, Loxton AG, Chegou NN, et al. Analysis of host responses to Mycobacterium tuberculosis antigens in a multi-site study of subjects with different TB and HIV infection states in subSaharan Africa. PLOS One 2013; 8(9): e74080. doi:10.1371/journal.pone.0074080.

5. Demissie A, Leyten EM, Abebe M, Wassie L, Aseffa A, Abate G, et al. Recognition of stage specific mycobacterial antigens differentiates between acute and latent infections with Mycobacterium tuberculosis. Clin Vaccine Immunol 2006; 13(2):179-186.

6. Caccamo N, Guggino G, Joosten SA, Gelsomino G, Di Carlo P, Titone L, et al. Multifunctional CD4(+) T cells correlate with active Mycobacterium tuberculosis infection. Eur J Immunol 2010; 40(8): 2211-2220.

7. Ireton GC, Greenwald R, Liang H, Esfandiari J, Lyashchenko KP, REED SG. Identification of Mycobacterium tuberculosis antigens of high serodiagnostic value. Clin Vaccine Immunol 2010; 17(10): 1539-1547.

8. Kashyap RS, Rajan AN, Ramteke SS, Agarwal VS, Kelkar SS, Purohit J, Taori GM, Daginawala HF. Diagnosis of tuberculosis in an Indian population by an indirect ELISA protocol based on detection of antigen 85 complex: a prospective cohort study. BMC Infect Dis 2007; 7: 74. doi:10.1186/1471-2334-7-74.

9. Kumar G, Dagur PK, Singh PK, Shankar H, Yadav VS, Daatoch VM, Bajaj B, Gupta R, Sengupta U, Joshi B. Serodiagnostic efficacy of Mycobacterium tuberculosis 30/32 kDa mycolyl transferase complex, ESAT-6 and CFP-10 in patients with active tuberculosis. Arch Immunol Ther Exp 2010; 58(1): 57-65.

10. Xueqiong $\mathrm{Wu}$, Yang $\mathrm{Y}$, Zhang J, Li B, Liang Y, Zhang $\mathrm{C}$, Dong $\mathrm{M}$, Cheng $\mathrm{H}$, He J. Humoral immune responses against the Mycobacterium tuberculosis 38-Kilodalton, MTB48 and CFP10/ESAT-6 antigens in tuberculosis. Clin Vaccine Immunol 2010; 17(3): 372-375.

11. Prabha C, Jalapathy KV, Das SD. Humoral immune response in tuberculous pleuritis. $\mathrm{Am}$ $J$ Immunol 2005; 1(2): 68-73.

12. Hoff ST, Abebe M, Ravn P , Range N, Malenganisho W, Rodriques DS, et al. Evaluation of Mycobacterium tuberculosis specific antibody responses in populations with different levels of exposure from Tanzania, Ethiopia, Brazil, and Denmark. Clin Infect Dis 2007; 45(5): 575-582.

13. Voller A, Bartlett A, Bidwell DE. Enzyme immunoassays with special reference to ELISA techniques. J Clin Path 1978; 31: 507-520.

14. Suraiya S, Musa M, Suppian R, Haq JA .Serological diagnosis for active tuberculosis in Malayasian population: comparison for four protein candidate. Asian Pac J Trop Dis 2012; 2: S312-S315. 